\title{
LA COMPRENSIÓN TEXTUAL EN FUNCIÓN DE LA ACENTUACIÓN ESPAÑOLA
}

Miriam Esther Dorta-Martínez ${ }^{1}$

Yemilka Rodríguez-Rodríguez ${ }^{2}$

Martha Antonia Souto-Padrón ${ }^{3}$

Universidad de Ciego de Ávila Máximo Gómez Báez (Cuba)

Recibido 14/01/2021 Aceptado 03/06/2021

La enseñanza-aprendizaje de la lengua materna exige actualmente su estudio como medio de cognición y comunicación. Se ha diagnosticado en la práctica pedagógica que prevalece la enseñanza de la acentuación española desvinculada de la comprensión textual. El artículo tiene el objetivo de proponer ejercicios sobre la comprensión textual en función de la acentuación española, a partir de la sistematización de la teoría y la práctica educativa y como parte de una tesis de pregrado, con el uso de los métodos analítico-sintético, inductivo-deductivo, la observación y el análisis de documentos. Los ejercicios muestran la posibilidad que tienen algunas lecturas del libro de texto de Español- Literatura y cuaderno complementario de octavo grado para el estudio de este contenido..

$\forall$ The teaching-learning of the mother tongue currently requires its study as a means of cognition and communication. It has been diagnosed in the pedagogical practice that the teaching of Spanish accentuation unrelated to textual understanding prevails. The article aims to propose exercises on textual comprehension based on Spanish accentuation, based on the systematization of educational theory and practice and as part of an undergraduate thesis, with the use of analytical-synthetic methods, inductive-deductive, observation and analysis of documents. The exercises show the possibility of some readings from the Spanish-Literature textbook and supplementary eighth grade notebook for the study of this content.

DOI

https://doi.org/10.15366/didacticas2021.24.006

PALABRAS CLAVE

1. miriamdm@sma.unica.cu

Enseñanza; Aprendizaje; Comprensión; Acentuación

KEYWORDS

Teaching; Learning; Understanding; Accentuation. 


\section{INTRODUCCIÓN}

Una de las misiones de la escuela cubana actual es hacer de sus educandos hombres que comprendan la esencia de los fenómenos y hechos que ocurren en su entorno y en el de los demás seres humanos. Hombres preparados para asumir los retos que la vida exige.

La comprensión textual ocupa un lugar relevante dentro de estas misiones por lo que debe ser tratada interdisciplinariamente, no obstante, a este componente se le debe conceder un tratamiento priorizado a través de aquellas asignaturas que privilegian el estudio de la Lengua Materna.

"La habilidad de comprensión desde el punto de vista lingüístico tiene su correlación con el proceso de comunicación, ya que para comprender se debe establecer un vínculo entre el autor y el lector a través del texto" (Roméu, 2003, p. 23).

Se concuerda con el criterio antes señalado, pues la autora concibe la comunicación como un proceso de intercambio de información a través de signos, mediante el cual se comparten experiencias, conocimientos y vivencias, lográndose una influencia mutua.

Es decir, que para comprender un texto se necesita analizar y construir significados y lo hará con mayor éxito el que tenga más conocimientos (universo del saber), tanto sobre el referente (realidad), como sobre los medios lingüísticos (fónicos, léxicos y gramaticales) empleados por el autor para significar.

Particularmente, el acento de las palabras constituye un referente fundamental para comprender el texto, pues su variación dentro de esta deviene en cambio de significado y por lo tanto se adecuará de acuerdo con el contexto y la intención comunicativa del autor. Con la integración de estos contenidos comprensión - acentuación se posibilita la preparación de los alumnos para el desarrollo de la habilidad oral y escrita y por ende de la comunicación. Permite que los educandos enfrenten el currículo de todas las asignaturas y a la vez conozcan y reflexionen acerca de diferentes temas de la realidad objetiva como parte de su preparación político-ideológica y de todas las esferas del saber.

Tradicionalmente los autores han abordado el contenido de la comprensión y la acentuación de forma separada. Referido al primero, autores como: García Alzola (1972), Rosario Mañalich (1990), Roméu (1992,1999), definen el concepto y como regularidad expresan que la comprensión textual es el resultado de una operación compleja y un proceso interactivo que tiene en cuenta la simultaneidad entre las señales del texto y la actividad del sujeto. Algunos señalan las etapas o niveles por los que transita el proceso.

De similar forma se procede con la acentuación. Abordan la temática: Ortografía Facultad Obrera y Campesina (1977); Cuadernos de Trabajo de Ortografía y Redacción de 7mo, 8vo y 9no grados (1983), de Olga Mendoza Martínez; Cuadernos de Trabajo de Ortografía 10mo grado (2001), de María Luisa García Moreno; 11no grado (2002), de Ana María Abello Cruz; 12mo grado (2003), de José Alberto López Díaz y Balmaseda Neyra, 
Osvaldo; Curso de Ortografía en Universidad para Todos (2002), de Ana María Abello. En ellos se enfatiza en la práctica constante de los contenidos ortográficos sobre acentuación mediante variados ejercicios.

Sin embargo, en los últimos años se ha dado un vuelco al estudio de la lengua, se han ido integrando los componentes funcionales de Comprensión, Construcción y Análisis con los contenidos lingüísticos. Ello se ha logrado a partir del enfoque cognitivo, comunicativo y sociocultural, cuya principal representante en Cuba ha sido A. Roméu, (1992, 1999, 2003, 2007) y sus seguidores: Fidelia Martín Oramas (2007), Leticia Rodríguez Pérez y Osvaldo Balmaseda Neyra (2009), Leticia Rodríguez (2014), Juan Ramón Montaño Calcines y Ana María Abello Cruz (2015), entre otros.

Se asumen los criterios de Angelina Roméu (2007) y Fidelia Martín Oramas (2007), por ser las autoras que han brindado los fundamentos teórico- metodológicos del enfoque cognitivo, comunicativo y sociocultural y por trabajar la comprensión vinculada con la acentuación, a partir del texto.

A nuestro juicio los autores han hecho un gran esfuerzo para que los estudiantes ejerciten el contenido sobre la comprensión y la acentuación pero aún es insuficiente la ejercitación sistemática en que se vincula la comprensión textual en función de la acentuación; se evidencia que los estudiantes continúan teniendo errores ortográficos en la acentuación que limitan la comprensión del texto.

Objetivo: Proponer ejercicios sobre la comprensión textual en función de la acentuación española, a través de lecturas del libro de Español- Literatura y cuaderno complementario de octavo grado.

\section{REFERENTES TEÓRICOS SOBRE LA COMPRENSIÓN TEXTUAL Y LA ACENTUACIÓN ESPAÑOLA}

La palabra comprensión se deriva de la voz latina comprehedere, y significa concebir una idea, abarcar, percibir, entender. La esencia semántica del término no ha variado: comprender significa apropiarse del significado de las ideas expuestas. (Diccionario de la RAE, 2008)

Como proceso, la comprensión significa, según García Alzola (1972), "entender, penetrar, concebir, alcanzar, discernir, descifrar (decodificar)", es decir, destejer significados y reconstruirlos, a partir de lo aportado por el texto, donde cada lector hará una lectura "individual", condicionada por su propia concepción del mundo, conocimiento del tema y competencia de las que dispone. (García, 1972, p. 42)

Según criterio de la doctora Rosario Mañalich (1990). Comprender es, sencillamente aplicar la inteligencia y el conocimiento previo a cualquier escrito que decidamos leer y entender. La verdadera comprensión de lo leído nos lleva a conclusiones, valoraciones 
críticas, a emitir juicios sobre la obra o el autor y nos permite establecer relaciones entre el contenido del texto con otros. Estudiosos de esta temática como: García Alzola, (1972) y Angelina Roméu (1999), expresan que la comprensión textual es el resultado de una operación compleja en la que se realizan numerosas operaciones, y que este procesamiento no sigue una sola dirección. Alegan que la mente no procede de una manera secuencial, sino por un proceso interactivo que tienen en cuenta la simultaneidad entre las señales del texto y la actividad del sujeto.

Como todo proceso, la comprensión textual transcurre por etapas que marcan el avance del receptor durante la atribución de significados y que favorecen, desde el punto de vista didáctico, la dirección del poceso de enseñanza aprendizaje. La profundización teórica al respecto reveló que diversos son los criterios acerca de cómo denominar los momentos o etapas por los que transcurre dicho proceso. Algunos autores, como García Alzola (1972), alude a los significados del texto (literal, implícito y complementario); otros se refieren a los niveles por los que transita el proceso: traducción, interpretación y extrapolación (Roméu, 1992), como lo hace esta autora.

A. Roméu propone la aplicación del enfoque comunicativo en la escuela media, criterio generalizado y que ha transformado el proceso de comprensión de textos en este nivel de enseñanza (Roméu, 1999, p.32) con la aplicación indispensable de los tres niveles de comprensión del texto.

De acuerdo con la profundización en la temática, Roméu (1999, 2003), ha considerado tres niveles de comprensión. Ellos son: la comprensión inteligente, la comprensión crítica y la comprensión creadora. Criterio que es fundamental para abordar este poceso vinculado con la acentuación española.

Estos autores alegan que la mente no procede de manera secuencial, sino por un proceso interactivo que tiene en cuenta la simultaneidad entre las señales del texto y la actividad del sujeto. Dentro de esas operaciones se encuentra el análisis de la palabra, dónde recae su acentuación y la relación entre el significado y el contexto, por lo que es necesaria una acertada comprensión del texto.

A juicio de las autoras cuando se habla de la exploración del texto, no debe faltar la observación de las palabras empleadas, el lugar que ocupa el acento, el significado para emitir las ideas y la explicación cognitiva, comunicativa y sociocultural que permita descubrir la funcionalidad de estas en relación con lo que significan en el texto (semántica), la intención y el contexto en que significan (pragmática). En esta última no deberán faltar preguntas como: ¿Con qué objetivo se utilizaron esas palabras? ¿Con qué finalidad se emplea determinada palabra con ese acento? ¿Significan lo mismo si le cambiáramos el acento? ¿Mantiene la categoría gramatical? ¿Se adecua a ese contexto su homófono?, entre otras preguntas para descubrir la intención comunicativa del autor.

$\mathrm{Al}$ comprender el texto es necesario tener presente los elementos ortográficos que contribuyen al logro de este propósito. Aprender ortografía es, por tanto, conocer las re- 
glas que rigen la escritura correcta de la palabra en nuestra lengua, así como el uso de los signos de puntuación y el empleo de la tilde para fijar gráficamente la pronunciación de las palabras, con ajustes a la norma culta.

En el libro Nueva ortografía para todos (2014) se define así el acento: "Al pronunciar aisladamente cualquier palabra polisílaba del español, no todas las sílabas que la componen se emiten y se perciben con el mismo relieve. Una de ellas destaca en el conjunto y resulta más perceptible que las demás. Esa diferencia en la pronunciación de una determinada sílaba, que establece un contraste entre ella y el resto de las que integran la palabra, recibe el nombre de acento". (Rodríguez, 2014, p. 316). En el trabajo se sigue este criterio de la definición de acento por referirse a la fuerza de pronunciación mayor que toda palabra tiene en una de sus sílabas.

Si importante es determinar el acento en una palabra aislada, más importante es hacerlo en un texto, en su contexto. En ambos casos se expresa un significado: perdida/ pérdida, pero más preciso es en un texto: La joven está perdida en estos tiempos / La joven está perdida en el pueblo / La joven llora por la pérdida de un familiar. Obsérvese que cuando varía el acento de la palabra en un texto o cuando se mantiene el propio acento en la palabra lo que cambia la significación es el contexto y la intención comunicativa del autor. Indudablemente hay mejor comprensión de lo que se nos comunica cuando las palabas aparecen en un texto. Por esta razón es de vital importancia trabajar de forma integrada la comprensión en función de la acentuación, a partir del texto.

Las ideas anteriores están avaladas por el estudio realizado en las últimas décadas, en que ha cobrado especial interés el papel social del lenguaje, mediante el cual se revela la diversidad de usos funcionales de la lengua, teniendo en cuenta los múltiplos contextos en los que el hombre se comunica. La ortografía con esta perspectiva comunicativa exige la integración de los criterios semántico, sintáctico y pragmático por lo que debe trabajarse a partir del texto. Tales ideas renovadoras se sustentan en el enfoque cognitivo, comunicativo y sociocultural y tienen como base los procesos de comprensión y producción de textos (Roméu, 2007).

Angelina Roméu (2007) ha definido el enfoque cognitivo, comunicativo y sociocultural como: "Una construcción teórica, resultado del complejo proceso de desarrollo de las nuevas concepciones lingüísticas que centran su atención en el discurso y en los procesos de comprensión y producción de significados en diferentes contextos (...) (Roméu, 2007, p. 8)

Este enfoque da respuesta al retraso de los programas de lengua, en los diferentes niveles, cuyos objetivos y contenidos se inscriben mayoritariamente en las concepciones de la enseñanza tradicional, normativa y formal, al no establecer los nexos entre los estudios de las estructuras lingüísticas y las necesidades comunicativas de los hablantes. 
La autora Martín Oramas (2007) contextualiza los postulados del enfoque cognitivo, comunicativo y sociocultural al estudio de la ortografía, enfoque que ha sido elaborado por Angelina Roméu (2007), razones por la cuales se asumen ambos criterios.

Para lograr una adecuada comprensión a partir del empleo de la acentuación se hace necesario dominar algunos aspectos sobre esta última. Los tipos o clases de acentos son: prosódico, la pronunciación se da en una sílaba de la palabra distinguiéndola de las demás por una mayor intensidad o por un tono más alto; el acento ortográfico: tilde que en la lengua escrita se coloca sobre la vocal de la sílaba tónica de algunas palabras, siguiendo unas determinadas reglas ortográficas; el acento diacrítico, mayor tono o intensidad con que se pronuncia la vocal de la sílaba tónica en algunas palabras para establecer el contraste entre las sílabas y diferenciar vocablos homónimos: el / él y el acento fonético, conjunto de particularidades fonéticas, rítmicas y melódicas que caracterizan el habla local regional o de un país haciéndolo diferente a los demás.

Las sílabas se clasifican en tónicas o átonas, las primeras son aquellas que se pronuncian con mayor intensidad, y las segundas, son pronunciadas con una menor intensidad.

Para lograr una adecuada comprensión es necesario descubrir en la palabra la sílaba donde aparece el acento y de acuerdo con el lugar que este ocupe así será su significado en el texto y la clasificación en: agudas, llanas, esdrújulas, sobresdrújulas. Existen palabras en la lengua que con solo la variación del acento cambia su categoría gramatical y su significado (ultimó, ultimo, último,). Solo el contexto y la intención del autor podrá determinar el significado y por ende habrá una mejor comprensión.

Las palabras agudas (oxítonas) son aquellas que tienen la mayor intensidad en la última sílaba (sílaba tónica). Llevan tilde cuando terminan en n, s o vocal: camión. No obstante, es necesario realizar una observación al respecto y es que cuando terminan en $\mathrm{s}$ precedidas de otra consonante no llevan tilde: robots.

En las palabras llanas (paroxítonas), la sílaba de mayor intensidad (sílaba tónica) es la penúltima, llevan tilde cuando no terminan en $\mathrm{n}$, s o vocal, o sea, contrario a las agudas: mesa.

Con respecto a las palabras esdrújulas (proparoxítonas), son aquellas en que la sílaba de mayor intensidad es la antepenúltima (sílaba tónica), siempre llevan tilde independientemente de cómo termine: música.

Cuando las palabras presentan encuentros vocálicos (diptongo, triptongo o hiato) llevan tilde según estén afectadas por las reglas generales de acentuación; no obstante, se debe observar las siguientes normas:

Los diptongos formados por una vocal abierta tónica (a, e, o) y una cerrada átona (i, u) o viceversa, la tilde se colocará siempre sobre la vocal abierta: miércoles, ilusión.

En relación con el hiato se señala que es la secuencia de dos vocales que no se pronuncian dentro de una misma sílaba, sino que conforman parte de las sílabas consecuti- 
vas. Existen tres clases de hiatos según el tipo de vocales que estén en contacto: Combinación de dos vocales abiertas iguales: cooperativa, vocal abierta más vocal abierta distintas: poeta, vocal abierta átona más vocal cerrada tónica o viceversa: gentío.

En todos estos casos, se colocará la tilde de acuerdo con las reglas generales de acentuación: proveer, poético, caoba.

Las palabras que presentan hiato del tipo c) llevarán tilde en la vocal cerrada, independientemente de que lo exijan o no las reglas generales de acentuación ortográfica: sonríe, tío, oído.

La h intervocálica no impide que se forme hiato como tampoco impide que este lleve tilde si lo requiere: vehículo, vahído.

Con respecto a los monosílabos por regla general, no llevan tilde: vio, fui, dio. No obstante, la Academia admite como correcta la acentuación gráfica de palabras como fíe, huí..., si quien escribe percibe el hiato en estas concurrencias vocálicas, y no las considera monosílabas, sino como palabras bisílabas. Constituyen excepciones los monosílabos con tilde diacrítica, que permiten diferenciar palabras con estructuras ortográficas similares, pero con distintos significados. (Alvero, 1999)

Los fundamentos teóricos ofrecidos anteriormente en cuanto a la acentuación de las palabras constituyen un instrumento de gran importancia para que sean utilizados en función de la comprensión. En el presente artículo se asume el contenido ortográfico de la acentuación en: las reglas generales de la acentuación en palabras agudas, llanas y esdrújulas, el diptongo e hiato y el acento diacrítico (tilde distintiva). En los ejemplos de ejercicios se integra la comprensión textual con los contenidos ortográficos seleccionados. Estos se imparten en 8vo grado. (MINED, Programa de Español-Literatura 8vo grado, 2004).

\section{SUGERENCIAS PARA EL EMPLEO DE LA COMPRESIÓN TEXTUAL EN FUNCIÓN DE LA ACENTUACIÓN ESPAÑOLA}

- Lectura en silencio.

- Determinación de las palabras que constituyan incógnitas léxicas.

- Comprensión general del texto.

- Localización de palabras en el texto en que la variación del acento conlleve a cambio de significado. (Pueden darse subrayadas)

- Explicación cognitiva, comunicativa y sociocultural de acuerdo con las dimensiones semántica, sintáctica y pragmática. 
Los ejemplos de ejercicios que se muestran a continuación se concibieron desde lecturas del Libro de texto: Español- Literatura (1991) y Cuaderno complementario de 8vo grado (2004). Aparecen actividades y la explicación de cada texto donde se evidencia la comprensión en determinados momentos a partir de la variación de la acentuación de algunas palabras.

1.- Lea atentamente el siguiente texto.

En mi caso, he dado algunas entrevistas también, bastante informales, aunque los periodistas las hayan formalizado con la habilidad que deben tener en eso. Pero hablar en público, sea pequeño o grande, nunca lo he hecho.

Tomado de Haydée habla del Moncada, Libro de texto, Español- Literatura 8vo grado, pág. 91.

a) Relea el texto anterior.

b) ¿Qué datos conocen de Haydée Santamaría? ¿Qué cualidades destacarías?

c) Busque las palabas cuyo significado desconozca.

d) ¿Qué idea se expresa en el texto?

e) El autor ha empleado la palabra público en el texto, ¿qué significación adquiere en él?

f) ¿Con qué intención ha sido empleada?

g) Divídela en sílaba y destaque la sílaba acentuada o tónica.

h) Clasifíquela de acuerdo con su acentuación.

i) Observe detenidamente la palabra público y llene los espacios en blanco según lo indicado:

\begin{tabular}{|l|l|l|}
\hline esdrújula & llana & aguda \\
\hline público & & \\
\hline
\end{tabular}

j) ¿A qué categorías o clases de palabras pertenece cada una?

k) ¿Si varía el acento a la palabra público cree que se corresponda con el significado que la autora lo ha concebido? Explique.

l) ¿Es intención del autor cambiar el significado de la palabra en ese texto? Fundamente.

En este ejercicio los alumnos se relacionan con una de las heroínas de la Revolución cubana, Haydée Santamaría, la cual participó en el asalto al cuartel Moncada y en la lucha insurreccional. El texto forma parte del testimonio que ofreció (1967) en charla con los estudiantes de la Universidad de La Habana. Se encuentra subrayada la palabra pú$\underline{\text { blico }}$ cuyo significado en este texto se refiere a que no estaba acostumbrada a hablar donde estuvieran reunidas tantas personas, sin embargo la intención es transmitir a los más 
jóvenes toda esa experiencia, sabiduría de los complejos momentos que atravesó un grupo de personas y ella en particular, para sembrar los cimientos de lo que después fuera el triunfo de la Revolución Cubana. Se aprecia la humildad, la modestia de esta mujer, pues realmente tenía mucho que contar sobre toda la actividad revolucionaria desarrollada en esa época.

Se prepara al alumno para que trabaje con la palabra (público) al dividirla en sílaba y destaque la tónica (pú). Por lo que según la clasificación es esdrújula. El significado de indicar conjunto de personas es el que se adecua en ese texto y es clave para la comprensión. El inciso i) hace al alumno razonar sobre la posibilidad de utilizar una misma palabra pero con diferente acento, lo que hace que cambie su categoría gramatical y por ende su significado, (publico) palabra llana y ahora utilizada como verbo en tiempo presente y (publicó) palabra aguda, verbo en pretérito, pero en el texto anterior no es intención de la autora expresar una idea que se ha mantenido en secreto, difundirla en ese momento o referirse a que ya se hizo. Este análisis revela la importancia que tiene el acento en la comprensión del texto según la variación en la palabra, su significado y el contexto en que se encuentre de acuerdo con la intención comunicativa.

2.- Lea atentamente el siguiente pensamiento:

"El hombre no muere cuando cesa de existir, sino cuando deja de amar". José de la Luz y Caballero (Cuaderno Complementario 8vo grado, pág. 60)

a) Relea cuidadosamente el pensamiento anterior.

b) ¿Qué conoce acerca de la personalidad de José de la Luz y Caballero?

c) Marque con una ( $\mathrm{x}$ ) la respuesta correcta. En el texto la palabra cesa significa: comienza acaba empieza

d) ¿Cuál es la palabra clave del texto?

e) El autor ha utilizado un artículo para acompañar al sustantivo hombre, ¿cuál es? Busque su homófono.

f) ¿Considera que si se utilizara el homófono acompañando al sustantivo conservaría la mis ma significación en el texto? ¿Por qué?

g) En el texto se ha empleado en dos ocasiones el vocablo cuando. Pruebe en uno de los casos tildarlo.

h) ¿Considera que esta nueva significación se corresponde con la intención del autor al expresar este mensaje? ¿Por qué?

i) ¿Es intención del autor utilizar esta palabra con tilde? ¿Por qué? 
Este pedagogo y filósofo fue considerado maestro por excelencia y formador de conciencias que engrandeció el sentido de la nacionalidad cubana. Para expresar esta gran idea se vale de una palabra clave, el sustantivo el hombre, el cual aparece acompañado del artículo el que anticipa género y número pero en este caso el masculino se emplea en sentido genérico, dígase hombres y mujeres. Se refiere al hombre como ser social que en sus relaciones ama, quiere, lo da todo con pasión, ya sea a su Patria, amigo, pareja; si lo ha dejado de hacer, ha muerto aunque físicamente siga viviendo y esta ha sido la intención del autor. No se logra igual comprensión si se utiliza el homófono él, ahora pronombre personal, con la tilde distintiva. No es intención destacar a determinado hombre sino a todos los seres humanos.

Se aprecia en el texto la utilización en dos ocasiones del vocablo cuando, en ambos casos como adverbio de tiempo que sirve de nexo introductorio a oraciones subordinadas adverbiales de tiempo para precisar el momento en que el hombre deja de existir. Se contrasta lo físico y lo espiritual, en que este último cobra gran valor. Si se tildaran estos vocablos utilizando el acento diacrítico (cuándo) se convertirían en adverbios interrogativos y cambiaría la significación, por ende la comprensión del texto. No es intención del autor preguntar por algo desconocido.

4. Lea el siguiente fragmento del Poema de Mío Cid:

El buen Cid Campeador hacia atrás volvió la cara; vio que entre ellos y el castillo quedaba mucha distancia manda volver la bandera y aguijar también les manda: “iHeridlos, mis caballeros, sin temor con vuestras lanzas, que con la merced de Dios nuestra será la ganancia!"

(Libro de texto, Español- Literatura 8vo grado, pág. 17)

a) Relea detenidamente el anterior texto.

b) En el texto la palabra aguijar significa: (Marca con una x la respuesta correcta)

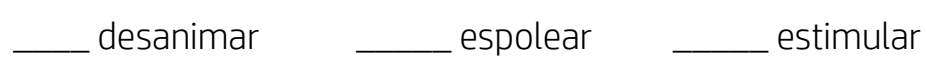

c) ¿Hacia dónde miró el Cid?

d) ¿Qué te sugiere en el texto la palabra hacia? ¿Cuál es su significación?

e) ¿Cuál es la sílaba tónica? ¿Cuál es la átona? ¿Cómo clasifica la palabra por su acentuación?

f) ¿A qué categoría gramatical corresponde?

g) ¿Qué vocales concurren en la palabra? ¿Qué se ha formado en cuanto a la contigüidad de vocales? 
h) Cambie el acento de la palabra (hacia) qué implicaciones tiene para el significado del texto. ¿Se pronuncian en la misma sílaba esas vocales? ¿Qué se ha formado en esa sílaba con respecto a las vocales? ¿Se mantendrá la misma comprensión?

i) ¿Expresaría lo mismo con el cambio de acento? (hacía) ¿Por qué?

El Poema de Mío Cid es la primera obra importante de la literatura española. Su figura central se llamaba Rodrigo Díaz de Vivar, pero fue denominado Mío Cid por los árabes y eso significa mi señor. Al comienzo del poema se destaca la actitud de este héroe para defenderse de los moros, voltea la cara para ver la posición del enemigo, la dirección precisa en que se encontraban, para ello utiliza la preposición (hacia) palabra llana, que al dividirla en sílaba se aprecia el diptongo (ia) en la sílaba átona -cia), con el significado de lugar y lo hace con la intención de ubicar la distancia para poder atacar, así manda a sus caballeros a empezar la batalla. Se podrá apreciar que el cambio de acento prosódico en la palabra (hacía) la mantiene llana, por la presencia del hiato, pero ha cambiado su categoría gramatical a verbo, del verbo hacer y a la vez su significado. Por lo tanto la variación de acento no corresponde a la intención del autor. Se vería afectada la comprensión en este caso. En los tres ejercicios tipos mostrados se aprecia cómo es posible emplear la comprensión del texto en función de la acentuación española. Ello nos permite una mejor comunicación.

\section{CONCLUSIONES}

El enfoque cognitivo, comunicativo y sociocultural deviene en fundamento teórico- metodológico de la enseñanza-aprendizaje de la comprensión y los contenidos relacionados con la acentuación española, lo cual tiene como categoría básica al texto.

Los ejercicios evidencian la posibilidad de estudiar la comprensión textual en función de la acentuación española para lograr en los estudiantes de octavo grado las habilidades comunicativas que se exigen en el nivel y en la preparación para la vida.

\section{REFERENCIAS}

ALVERO, F. (1999): Lo esencial en la ortografía. La Habana: Editorial Pueblo y Educación.

ABELLO, A. (2002): Curso de Ortografía. Universidad para Todos. La Habana: Editorial Juventud Rebelde.

ABELLO, A. (2002): Ortografía. Cuaderno de trabajo undécimo grado. La Habana: Editorial Pueblo y Educación. 
DICCIONARIO DE LA RAE: (2008). Microsoft ${ }^{\circledR}$ Encarta ${ }^{\circledR} @ 191993-2007$ Microsoft Corporation.

GARCÍA, E. (1972): Lengua y Literatura. La Habana: Editorial Pueblo y Educación.

GARCÍA, \& LEÓN, (2001): Cuaderno de trabajo de Ortografía décimo grado. La Habana: Editorial Pueblo y Educación.

LÓPEZ, \& BALMASEDA (2003): Ortografía. Cuaderno de trabajo duodécimo grado. La Habana: Editorial Pueblo y Educación.

MAÑALICH, R. (1990): Taller de la palabra. La Habana: Editorial Pueblo y Educación.

MARTÍN, F. (2007): "Propuesta metodológica basada en el enfoque cognitivo, comunicativo y sociocultural para el desarrollo de la competencia ortográfica”. En: El enfoque cognitivo, comunicativo y sociocultural en la enseñanza de la lengua y la literatura. La Habana: Editorial Pueblo y Educación, pp. 329-343.

MENDOZA, O. (1983): Ortografía y Redacción. Cuaderno de Trabajo. La Habana: Editorial Pueblo y Educación.

MINED. (2004): Programa de Español - Literatura 8vo grado. La Habana: Editorial Pueblo y Educación.

MINED. (2004): Español octavo grado. Cuaderno complementario. Ciudad de La Habana: Editorial Pueblo y Educación.

MONTAÑO, \& ABELLO, (2015): Leer y escribir, ¡Tarea de todos! La Habana: Editorial Pueblo y Educación.

ORTOGRAFÍA FACULTAD OBRERA Y CAMPESINA (1977): (Quinta edición). La Habana: Editorial Pueblo y Educación.

RODRÍGUEZ, L. (1991): Libro de texto Español- Literatura octavo grado. La Habana: Editorial Pueblo y Educación.

RODRÍGUEZ, \& BALMASEDA (2009): Actividades para leer, pensar y disfrutar. Ciudad de La Habana: Editorial Pueblo y Educación.

RODRÍGUEZ, L. (2014): La nueva Ortografía para todos. La Habana: Editorial Pueblo y Educación.

ROMÉU, A. (1992): Aplicación del enfoque comunicativo en la escuela media. La Habana: IPLAC $(\mathrm{S} / \mathrm{P})$.

ROMÉU, A. (1999): "Naturaleza interdisciplinaria del estudio del texto", en Revista Varona (28), enero- junio (52-56), La Habana.

ROMÉU, ANGELINA (2003). Teoría y práctica del análisis del discurso. La Habana: Editorial Pueblo y Educación. 
ROMÉU, A. (2007): "El enfoque cognitivo, comunicativo y sociocultural en la enseñanza de la ortografía”. En: El enfoque cognitivo, comunicativo y sociocultural en la enseñanza de la lengua y la literatura. La Habana: Editorial Pueblo y Educación, pp.315328. 